\title{
USING FUZZY SETS IN THE ESTIMATION SYSTEM OF THE EFFICIENCY OF URBAN ENVIRONMENT METABOLISM (ON THE EXAMPLE OF CITIES OF UKRAINE)
}

\author{
Igor PATRAKEYEV ${ }^{(D *}$, Victor ZIBOROV ${ }^{(D)}$ \\ Faculty of Geoinformation Systems and Territory Management Technologies, \\ Kyiv National University of Construction and Architecture, Kyiv, Ukraine
}

Received 15 January 2019; accepted 18 September 2019

\begin{abstract}
The urban environment is a networked metabolic organism. The urban environment includes networks that feed it with energy, resources, people, goods and information. The urban environment carries out a permanent transformation of matter, energy and produces waste, which together change the urban environment. We have proposed to use an indicator for assessing the efficiency of the metabolism of the urban environment, which allows to take into account the relationship between the urban structure, energy consumption, emissions of pollutants and the intensity of consumption of natural resources. We use this indicator as a tool for forecasting sustainable urban development. Using the example of Poltava city, we have shown that the indicator for assessing the metabolic efficiency of the urban environment can be used as one of the decision-making tools for the sustainable development of Ukrainian cities. The improvement of existing and development of new indicators is an important task towards the implementation of the concept of sustainable development, which is a logical continuation of the teachings of V. I. Vernadsky on the noosphere.
\end{abstract}

Keywords: resource flows, energy balance, free energy, metabolism of the urban environment, material-energy streams, fuzzy logic.

\section{Introduction}

Today, our civilization is experiencing an "urban era". Therefore, issues related to the effective management of energy consumption and energy consumption for recycling in cities are relevant.

In this regard, special attention is paid to the concept of "energy balance" in the urban environment, which was proposed by the working group of the World Energy Council: the energy produced must cover the energy consumed (Newman, 2004).

The city is a non-equilibrium system. The state of imbalance is determined by the scale of anthropogenic pressures on the environment. Indicators of anthropogenic load can be: population density, area of settlements, the load from the weight of buildings and structures, industrial production, the level of motorization, etc. (Bolshakov, 2002; Karavaeva, Levchenko, \& Trohimenko, 2011).

Modern research is aimed at creating indicators and other tools to support decision-making on the implementation of strategies for low-carbon development of society and reducing the depletion of natural resources (Patrakeyev, 2015).

In a large number of studies (Bolshakov, 2002; Karavaeva, Levchenko, \& Trohimenko, 2011), attention is paid to assessing the quality of the urban environment. In accordance with the urban welfare index developed by the McKinsey Global Institute, the urban development environment is characterized by indicators of population density, public transport intensity and the degree of greening of public places.

The purpose of the article is to examine the method for constructing an indicator of efficiency of the urban environment metabolic (UEM). This indicator allows to take into account the relationship between the urban structure, energy consumption, emissions of pollutants and the intensity of consumption of natural resources. Formally, this indicator is built on the mathematical apparatus of fuzzy logic, taking into account incomplete and inaccurate knowledge. This method is used by us on the example of cities in Ukraine.

*Corresponding author. E-mail: ipatr@ukr.net 


\section{Method for assessing the metabolic efficiency of the urban environment}

This method is based on the concept of black box systems. With this approach, emphasis is placed on the balance of material, energy and information flows. Meanwhile, the interaction of the processes that generate this balance receives much less attention.

According to Odum (1998), and Lotka (1998), every social or living system is governed by the fundamental laws of conservation of power (Santamouris, 2004). According to the law of conservation of power, the total power at the entrance to the system is equal to the sum of the active powers and the loss power at the system output:

$$
N=P+L,
$$

where $N$ is the total power of the system; $P$ is active (useful) power of the system; $L$ is the loss power of the system.

From this law it follows that any change in the active power is compensated by the change in the power of losses and is controlled by the total power of the system.

Urban environment can be considered as a set of interacting subsystems. From a functional point of view, the most significant subsystems of the urban environment can be considered the transport subsystem, the subsystem of the urban economy and the socio-economic subsystem (Bertalanffy, 2004; Kennedy, Cuddihy, \& Engel-Yan, 2007).

The transport subsystem is characterized by population and cargo mobility. As a result of the functioning of this subsystem, energy is released, $\mathrm{CO}_{2}$ emissions are increasing, and emissions of other pollutants from the urban environment are also increasing.

The urban economy subsystem is characterized by the total amount of consumed material and energy flows, residential area per inhabitant. The urban economy is also characterized by the amount of relevant waste generated by the vital processes in the urban environment.

The socio-economic subsystem is characterized by the amount of gross domestic product produced by the city's enterprises, the number of jobs, the number of students, the amount of energy, water, waste, the number of taxes per capita, and so on.

Each of the subsystems under consideration can be abstractly represented as a flowchart of interaction with the environment, as shown in Figure 1.

Supporting the livelihoods of the urban environment is the circulation of substances (Butera \& Caputo, 2008). That is, the very existence of the urban environment depends on the constant flow of the external energy flow $N(t)$, which is necessary for the life of both living organisms and for the production of materials, substances, products, resources and services.

The subsystem receives a certain amount of various types of energy, matter and information $N(t)$. In addition, the subsystem produces two types of products. One type of product is a negative product, it is determined by the loss stream $L(t)$. And another type of product is used by each subsystem to ensure its own life activity. This type is determined by the useful work flow $P(t)$ (Bolshakov, 2002).

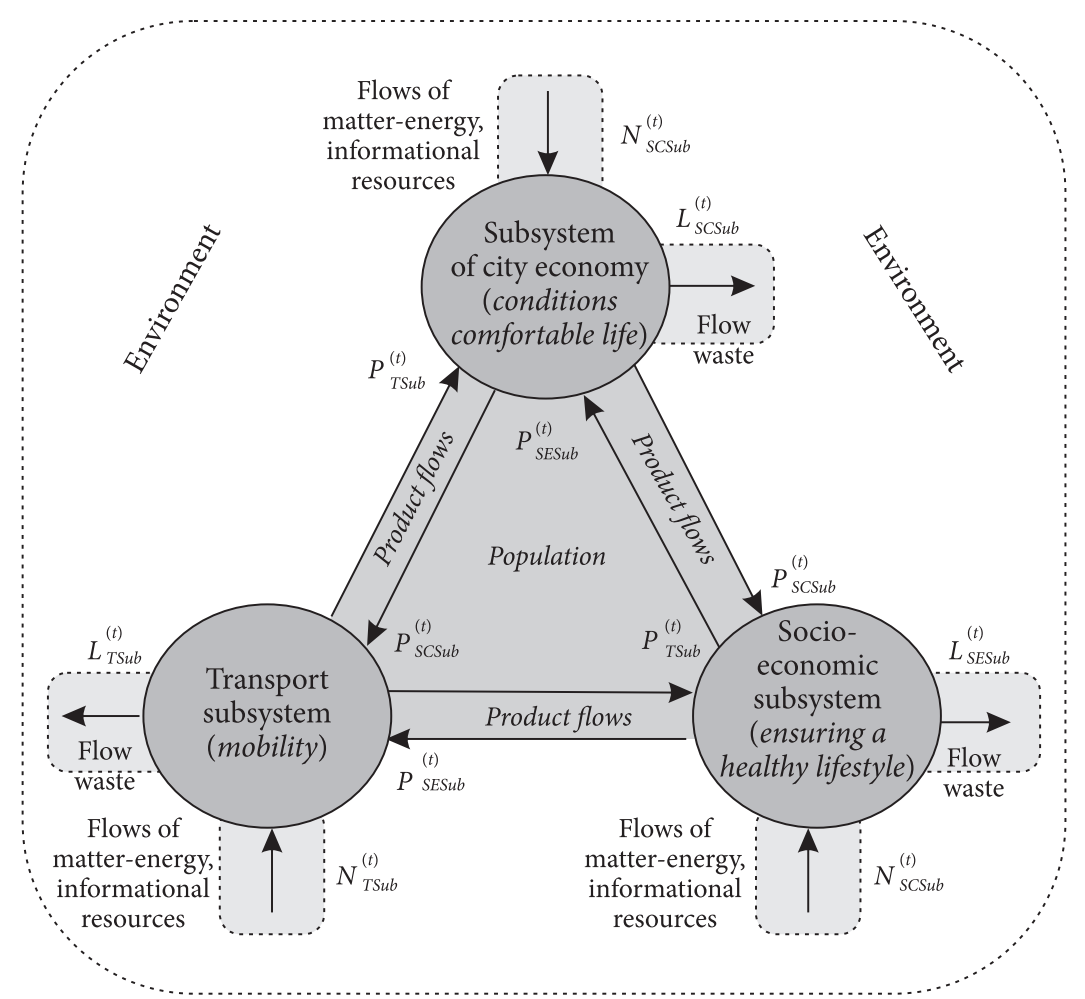

Figure 1. The scheme of exchange of material resources, information and energy between the environment and subsystems of the urban environment 
Each of the subsystems of the urban environment discussed above has its own effectiveness $\xi_{i}$. This efficiency depends on the energy costs in each of the subsystems. In aggregate, each of the subsystems contributes to a comprehensive assessment of the efficiency of the metabolism of the urban environment.

Thus, two questions arise. First, how to measure the effectiveness of each of the subsystems of the urban environment. And secondly, how to integrate the effectiveness scores of each of the subsystems $\xi_{i}$ to obtain a general integrated assessment of the effectiveness of the metabolism of the urban environment. The integration of different types of data into a single information space provides the possibility of comprehensive data analysis. This approach allows us to obtain new knowledge about the urban environment (Urban development and urban metabolism: A spatial approach, 2013).

\section{Fuzzy model for assessing the metabolism of the urban environment}

To simulate multidimensional dependencies, such as MISO (multiple input, single output), it is advisable to use a hierarchical fuzzy logic output system. The advantage of such hierarchical systems is their compactness. A small number of fuzzy rules (Lozano \& Gutierrez, 2008) can adequately describe the multi-dimensional dependencies "multiple input, single output". The use of a hierarchical system of fuzzy inference makes it possible to overcome the "Curse of dimensionality", when, with a large number of inputs, it is difficult for an expert to describe causal relationships in the form of fuzzy rules (Chekmarev, 2010).

The Takagi-Sugeno-Kang (TSK) model (Haurie \& Viguier, 2004) has gained the most popularity among fuzzy inference systems. In the TSC, the function of the conclusion is determined by a fuzzy, but pointwise way. Various aspects related to the theory of design and the use of fuzzy logic systems are discussed in detail in numerous monographs (Yanshin, 2007; Chekmarev, 2010; Tistol, 2013).

To evaluate the effectiveness of UEM, we use a mathematical model based on fuzzy logic.

Consider the task of evaluating input primary indicators (variables) $x_{1}, \ldots, x_{k}, \ldots, x_{n}$ (leaves of a tree structure, Figure 2) as fuzzy variables, for each of which you can assign three membership functions $\mu_{k}^{1}, \mu_{k}^{2}, \mu_{k}^{3}$.

Each of the measured values of the primary indicators of the material-energy and information flows of the urban environment can refer to one of three fuzzy statements (Santamouris, 2004):

- the value $x_{k}$ corresponds to small quantity;

- the value $x_{k}$ corresponds to average quantity;

- the value $x_{k}$ corresponds to large quantity.

Each fuzzy statement is characterized by a corresponding therm-set $A_{k}^{j}$ and has a corresponding membership function of $\mu_{k}^{j}$, where $j \in\{1,2,3\}$. This function characterizes the degree to which the value belongs to the terms "small quantity", "average quantity", "large quantity". On

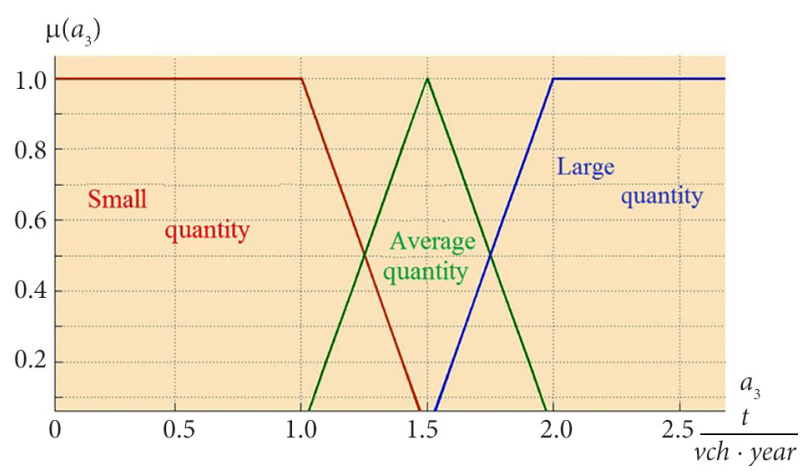

Figure 2. Example of phase-out of $\mathrm{CO}_{2}$ emissions produced by private motor vehicles (primary indicator of $a_{3}$ )

the basis of this, one can construct $m=3^{n}$ antecedents of the TSK production rules in the form (Santamouris, 2004; Harvey, 2011):

$$
\begin{aligned}
& R^{(1)} \text { IF } x_{1} \text { IS } A_{1}^{1} \text { AND } x_{2} \text { IS } A_{2}^{1} \text { AND... } \\
& \ldots \text { AND } x_{n} \text { IS } A_{n}^{1} \text { THEN } y_{1}=f\left(x_{1}, \ldots, x_{n}\right), \\
& \ldots \\
& R^{(m)} \text { IF } x_{1} \text { IS } A_{n}^{1} \text { AND } x_{2} \text { IS } A_{n}^{2} \text { AND... } \\
& \ldots \text { AND } x_{n} \text { IS } A_{n}^{n} \text { THEN } y_{m}=f\left(x_{1}, \ldots, x_{n}\right),
\end{aligned}
$$

If we use operations $\wedge$ (AND), then fuzzy logic output system of TSK can be rewritten into a compact (vector) view:

$$
\left[\prod_{k=1}^{n}\left(x=A_{k}^{j}\right)\right] \rightarrow y_{i}=f\left(x_{1}, \ldots, x_{n}\right), \quad i=\overline{1, m} .
$$

Figure 2 shows an example of phase-out of $\mathrm{CO}_{2}$ emissions produced by private motor vehicles (see Table 1 , variable $a_{3}$ ) with the use of appropriate thermo-sets: $A_{a_{3}}^{1}$ - "small quantity", $A_{a_{3}}^{2}$ - "average quantity", $A_{a_{3}}^{3}-$ "large quantity".

Each of the term sets is characterized by the corresponding membership function, which can be given analytically by the following expression:

$$
\begin{aligned}
& \mu_{a_{3}}^{1}=\left\{\begin{array}{lll}
1 & \text { if } & 0 \leq a_{3} \leq 1 ; \\
\frac{1.5-a_{3}}{0.5} & \text { if } & 1<a_{3}<1.5 ; \\
0 & \text { if } & 1.5 \leq a_{3} .
\end{array}\right. \\
& \mu_{a_{3}}^{2}=\left\{\begin{array}{lll}
0 & \text { if } a_{3} \leq 1 ; \\
\left(a_{3}-1\right) / 0.5 & \text { if } \quad 1<a_{3}<1.5 ; \\
\left(2-a_{3}\right) / 0.5 & \text { if } 1.5<a_{3}<2 ; \\
0 & \text { if } \quad 2 \leq a_{3} .
\end{array}\right. \\
& \mu_{a_{3}}^{3}=\left\{\begin{array}{lll}
0 & \text { if } & a_{3} \leq 1.5 ; \\
\frac{1.5-a_{3}}{0.5} & \text { if } & 1.5<a_{3}<2 ; \\
1 & \text { if } \quad 2 \leq a_{3} .
\end{array}\right.
\end{aligned}
$$


Table 1. A fragment of the primary indicators of the material and energy flows of the urban environment (this is an example of the transport subsystem)

\begin{tabular}{|l|l|l|l|l|l|}
\hline \multicolumn{1}{|c|}{$\begin{array}{c}\text { Primary indicators of the material-energy } \\
\text { flows of the urban environment }\end{array}$} & Denotation & $N(t)$ & $P(t)$ & $L(t)$ & $\begin{array}{c}\text { Units of } \\
\text { measurement }\end{array}$ \\
\hline 1. The density of the street and road network & $a_{1}$ & & & $\frac{\mathrm{km}}{\mathrm{km}^{2}}$ \\
\hline 2. Share of carbonless transport ("green transport") & $a_{2}$ & & & $\%$ \\
\hline $\begin{array}{l}\text { 3. Volume of } \mathrm{CO}_{2} \text { emissions produced by private motor } \\
\text { vehicles }\end{array}$ & $a_{3}$ & & & $\frac{t}{v c h \times \text { year }}$ \\
\hline $\begin{array}{l}\text { 4. Volumes of nitrogen of } \mathrm{NO}_{x} \text { emissions produced by } \\
\text { passenger cars }\end{array}$ & $a_{4}$ & & & $\frac{\mathrm{kg}}{v c h \times \text { year }}$ \\
\hline 5. Volume of $\mathrm{CO}_{2}$ emissions produced by public transport & $a_{5}$ & & & $\frac{t}{v c h \times \text { year }}$ \\
\hline
\end{tabular}

Each membership function $\mu_{a_{3}}^{1}, \mu_{a_{3}}^{2}, \mu_{a_{3}}^{3}$ generates normally-convex unimodal fuzzy sets $A_{a_{3}}^{1}, A_{a_{3}}^{2}, A_{a_{3}}^{3}$ with corresponding kernels of each fuzzy set

$$
\begin{aligned}
& w_{a_{3}}=\operatorname{core}\left(A_{a_{3}}^{1}\right)=1 ; \\
& m_{a_{3}}=\operatorname{core}\left(A_{a_{3}}^{2}\right)=1.5 ; \\
& b_{a_{3}}=\operatorname{core}\left(A_{a_{3}}^{3}\right)=2,
\end{aligned}
$$

where $w_{a_{3}}, m_{a_{3}}, b_{a_{3}}$ are a clear values for determining the "small quantity", "average quantity" and "large quantity" for the variable $a_{3}$ respectively.

Clear values $w_{a_{3}}, m_{a_{3}}, b_{a_{3}}$ for each primary indicator depend on various factors. These factors can be as follows: environmental quality standards, economic development programs of the city, regulatory and technical documentation, legal standards for the development of engineering and transport infrastructure of the city, and so on. Depending on the value of the primary indicator of $x_{k}$, the $w_{a_{3}}<m_{a_{3}}<b_{a_{3}}$ or $w_{a_{3}}>m_{a_{3}}>b_{a_{3}}$ relationships may occur.

According to the primary indicator of the $a_{3}$, we have the following conditions:

$$
\begin{aligned}
& \mu_{a_{3}}^{1}\left(a_{3}\right)=1 \quad \text { if } \quad a_{3} \leq w_{a_{3}} ; \\
& \mu_{a_{3}}^{2}\left(m_{a_{3}}\right)=1 ; \\
& \mu_{a_{3}}^{3}\left(a_{3}\right)=1 \quad \text { if } \quad a_{3} \geq b_{a_{3}} .
\end{aligned}
$$

In order to provide flexibility, the importance level of $p_{k}$ for each primary indicator of $x_{k}$ is used in the calculation of the indicator of the UEM estimation. The higher the value of $i_{k}$, the more important the influence of the primary indicator of $x_{k}$ on the indicator of the effectiveness evaluation of UEM. $x_{k}$ Five important levels are used to assess the effectiveness of the UEM: $p_{k}=1,2,3,4,5$.

Next, you need to select three piecewise linear functions of $f_{k}^{1}, f_{k}^{2}, f_{k}^{3}$ for each input variable of $x_{k}$.
The $f_{k}^{j}$ function corresponds to the contribution of the variable $x_{k}$ to the final UEM performance indicator. We assume that we evaluate the case, corresponding to the rules of the (IF $\left.x_{k} I S A_{k}^{j}\right)$, where the $p_{k}>p_{l}$ for all $l \neq k$.

Functions of the $f_{k}^{j}$ are chosen in concert with respect to the functions of the membership of the $\mu_{k}^{j}$ :

$f_{k}^{1}\left(x_{k}\right)=0, \forall x_{k} \leq m_{k} \vee \forall x_{k} \leq b_{k} ;$

$f_{k}^{2}\left(x_{k}\right)=50, \forall x_{k} \leq m_{k} \wedge \forall x_{k} \leq b_{k} \vee \forall x_{k} \leq m_{k} \wedge \forall x_{k} \leq w_{k}$;

$f_{k}^{3}\left(x_{k}\right)=100, \forall x_{k} \geq b_{k} \vee \forall x_{k} \leq m_{k}$.

The function $f_{k}^{j}$ is non-decreasing and complies with the restrictions:

$$
0 \leq f_{k}^{j}\left(x_{k}\right) \leq 100 \text {. }
$$

Condition (4) requires that the interval of values of the indicator of the evaluation of the effectiveness of the UEM be between 0 and 100 .

Figure 3 shows the piecewise linear functions of the $f_{a_{3}}^{1}, f_{a_{3}}^{2}, f_{a_{3}}^{3}$ which satisfy the constraints $(1-4)$ and

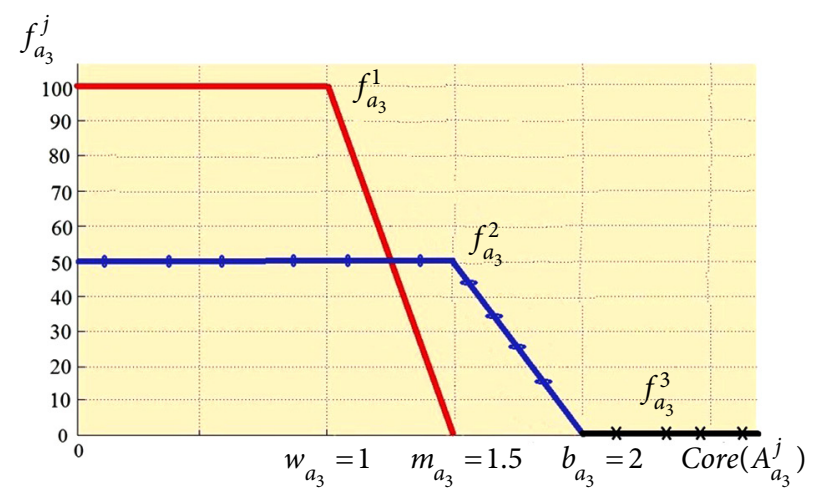

Figure 3. An example of a function of $f_{a_{3}}^{j}$ that is consistent with the membership functions shown in Figure 2 and meets the constraints (1-4) 
are agreed upon with the corresponding functions of the $\mu_{a_{3}}^{1}, \mu_{a_{3}}^{2}, \mu_{a_{3}}^{3}$ membership. $\mu_{b_{29}}^{1}, \mu_{b_{29}}^{3}$ As can be seen from Figure 3, the greatest power in the integral estimation brings the variable $c_{39}$, when the condition of the production of $\left(\begin{array}{llll}I F & a_{3} & \text { IS } & A_{a_{3}}^{1}\end{array}\right)$ takes the value of "truth".

Fuzzy mathematical model of the indicator of the evaluation of the effectiveness of UEM in the form of a set of TSK rules can be presented in the form (Paola, Giulia, \& Marco, 2016):

$$
R^{(i)}: I F \prod_{i=1}^{m}\left(x_{k} I S A_{k}^{j}\right) \text { THEN } y_{i}=\sum_{k=1}^{n} \frac{p_{k}}{P} \times f_{k}^{j}(x)
$$

where $i$ is number of TSK rules $(i=\overline{1, m}) ; n$ is number of conditions; $k$ is serial number of the input variable; $x_{k}$ is input variable $(k=\overline{1, n}) ; \quad A_{k}^{j}$ is fuzzy set with associated membership function of $\mu_{k}^{j}, j \in\{1,2,3) ; p_{k}$ is coefficient of importance of the input variable of $x_{k} ; P=\sum_{i=1}^{n} p_{k}$.

In accordance with condition (4), it is necessary to ensure the implementation of inequality: $0 \leq y_{i} \leq 100$.

Fuzzy logical conclusion for $m$ of the number of TSKrules is given in the form:

$$
y_{\alpha}=\frac{\sum_{i=1}^{m} w_{i} \times y_{i}}{\sum_{i=1}^{m} w_{i}}=\frac{\sum_{i=1}^{m} w_{i} \times \sum_{k=1}^{n} \frac{p_{k}}{P} \times f_{k}^{j}\left(x_{i}\right)}{\sum_{i=1}^{m} w_{i}},
$$

where $\alpha$ is intermediate level of computation of the overall hierarchical structure of the indicator of the effectiveness of the UEM after the received input data; $w_{i}$ is weight factor $i$-th rule that characterizes the level of activation TSK-rule, if the level of activation is determined by the t-norm from:

$$
w_{i}=\min \left\{\mu_{A_{1}^{1}}\left(x_{1}\right), \mu_{A_{2}^{1}}\left(x_{2}\right), \ldots, \mu_{A_{n}^{1}}\left(x_{n}\right)\right\} .
$$

Interim evaluations at the $\alpha$ level will be new input variables for interim evaluations at the $\alpha+1$ level.

Let us consider an example of the use of piecewise linear functions of $f_{a_{3}}^{1}, f_{a_{3}}^{2}, f_{a_{3}}^{3}$ (Figure 3) to obtain an intermediate estimate at the $\alpha$ level. Suppose that in the simplest case, if the value of the primary indicator:

$$
x_{k} \leq w_{k}, \mu_{A_{k}^{2}}\left(w_{k}\right)=0, \mu_{A_{k}^{3}}\left(w_{k}\right)=0, k \in \overline{1, n},
$$

then $y_{i}=y_{\alpha}=0$, if $f_{k}^{1}\left(x_{k}\right)=0$;

$$
m_{k} \leq x_{k} \leq b_{k}, \mu_{A_{k}^{1}}\left(m_{k}\right)=0, \mu_{A_{k}^{3}}\left(b_{k}\right)=0, k \in \overline{1, n},
$$

then $y_{i}=y_{\alpha}=50$, if $f_{k}^{2}\left(x_{k}\right)=50$;

$$
x_{k} \geq b_{k}, \mu_{A_{k}^{1}}\left(b_{k}\right)=0, \mu_{A_{k}^{2}}\left(b_{k}\right)=0, k \in \overline{1, n},
$$

then $y_{i}=y_{\alpha}=100$, if $f_{k}^{3}\left(x_{k}\right)=100$.

In the general case, at the intermediate level of the $\alpha$, the computation of the efficiency of the UEM will depend on the level of activation of the $w_{k}$ of each TSK-rule that is determined by the t-norm.

To evaluate the generalization indicator UEM, we have identified equal importance indices for intermediate values.

For the level of the $\alpha>1$ hierarchy, we calculate the arithmetic mean $\bar{y}_{\alpha+1}$ weighed for the set of numbers of $\bar{y}_{l}$ with positive real weight coefficients. This calculation will be performed for each of the subsystems under study in the urban environment:

$$
\bar{y}_{\alpha+1}=\frac{\sum_{l=1}^{v} v_{l} \times \bar{y}_{l}}{\sum_{l=1}^{v} v_{l}},
$$

where $\bar{y}_{l}$ is the number of exits at the level of the hierarchy of the $\alpha ; v_{l}$ is positive actual weighting coefficient for each subsystem of the urban environment.

Elements of the hierarchical structure of the integrated evaluation of the effectiveness of UEM are shown in Figure 4.

They are interpreted as follows:

- the root of the tree hierarchy is an integral assessment of the effectiveness of the UEM $\left(I_{\Sigma}\right)$;

- $\bar{\alpha}, \bar{\beta}, \bar{\gamma}$ are the evaluations of the metabolic efficiency for each of the subsystems under study in the urban environment;

$-\overline{\alpha_{1}}, \overline{\alpha_{2}}, \overline{\alpha_{3}}, \overline{\beta_{1}}, \overline{\beta_{2}}, \overline{\beta_{3}}, \overline{\gamma_{1}}, \overline{\gamma_{2}}, \overline{\gamma_{3}}$ are the quantities that characterize metabolic transformations. They affect the overall assessment of the effectiveness of UEM $\left(I_{\Sigma}\right)$;

$-a_{1}, \ldots, a_{5} ; b_{1}, \ldots, b_{6} ; c_{1}, \ldots, c_{7}$ are the terminal vertices of the tree of the hierarchy are primary indicators. They characterize the energy, material and information flows of the urban environment.

Each of the subsystems of the urban environment has three levels of data. The first level is the measured primary indicators. The second level is an interim evaluation. These estimates characterize the flow of energy consumed. This energy is a measure of the real capacity of the urban environment. The third level is the flow of losses, that is, the power of losses. These losses are a measure of lost opportunities in the urban environment. In conclusion, three evaluations of the efficiency of each of the subsystems are synthesized in the final integrated evaluation of the effectiveness of the UEM. Therefore, the structure of the integrated assessment of the effectiveness of the UEM is four levels of the hierarchy.

Cities of Ukraine are a typical model of a modern industrial city. Strong zoning of the territory led to the use of land in two main directions. One zone is intended for industry, the other zone is intended for housing. At the same time, such zones are intentionally located at distances that imply the need for an efficient transport system. This system connects residential buildings and workplaces (Enkvist, Naucler, \& Rosander, 2007). Thus, the system creates a form of "compulsory mobility". Today, the post-Soviet cities are very far from the EU cities in 


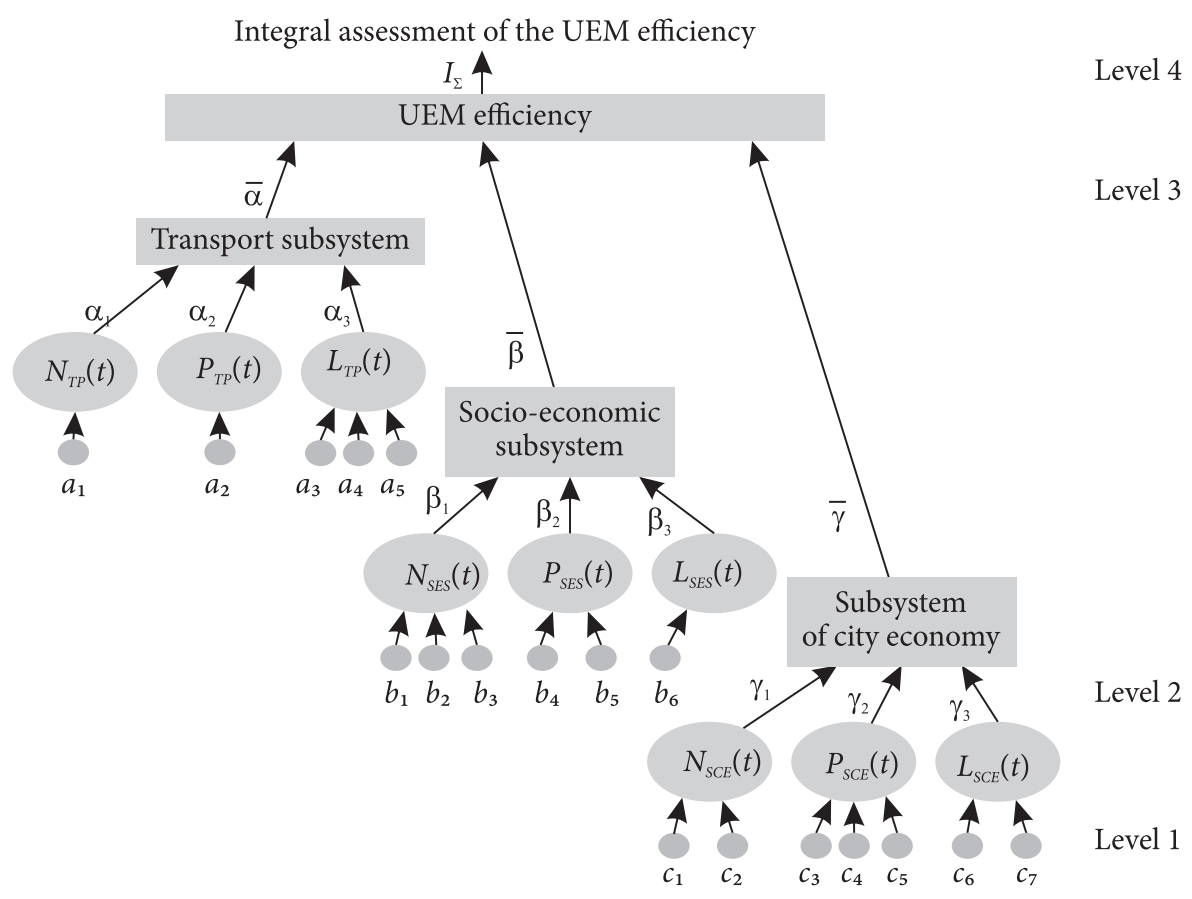

Primary indicators of the material-energy streams of the urban environment

Figure 4. Hierarchical structure of the evaluation of the effectiveness of the metabolism of the urban environment

terms of the effectiveness of the metabolism of the urban environment.

\section{Approval of the fuzzy model of the indicator of the efficiency of the metabolism of the urban environment}

To prepare the initial data, we used the GIS capabilities for the formation of geospatial models and thematic layers. This corresponds to the primary indicators presented in Table 1. In total, the table contains 37 basic primary indicators. These indicators characterize the metabolic

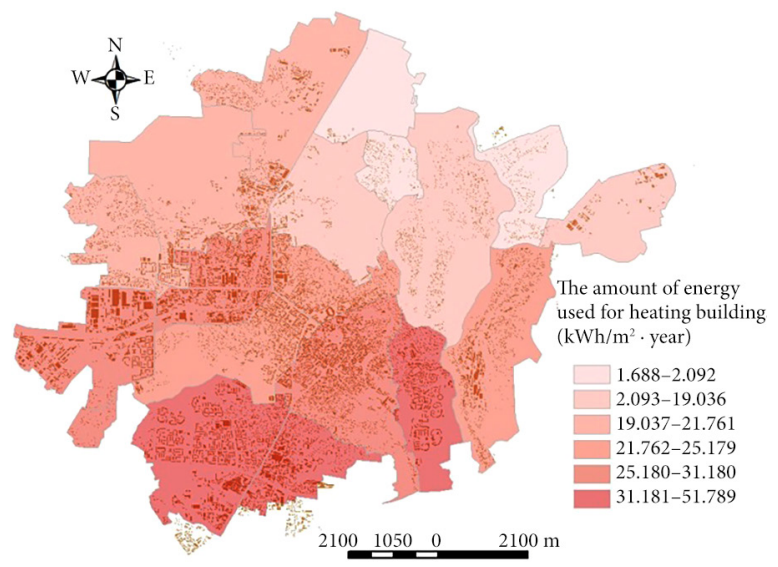

Figure 5. Geoinformation modeling of the urban environment by indicatirs of amount of energy used for heating buildings $\left(\mathrm{kWh} / \mathrm{m}^{2}\right.$ per year $)$ transformations of the three subsystems of the urban environment of Poltava city. Geographic or spatial data is the basic component of the assessment of the quality of the urban environment. These data are presented in the form of digital data on spatial objects. They include information about their location, properties, their spatial and non-spatial attributes, see Figure 5 and Figure 6.

One of the interaction measures of the UEM and geographic information system performance evaluation model is the interface developed by the MatLab software (The MathWorks Inc) with the widespread ArcGIS 10 (Allen, 2009).

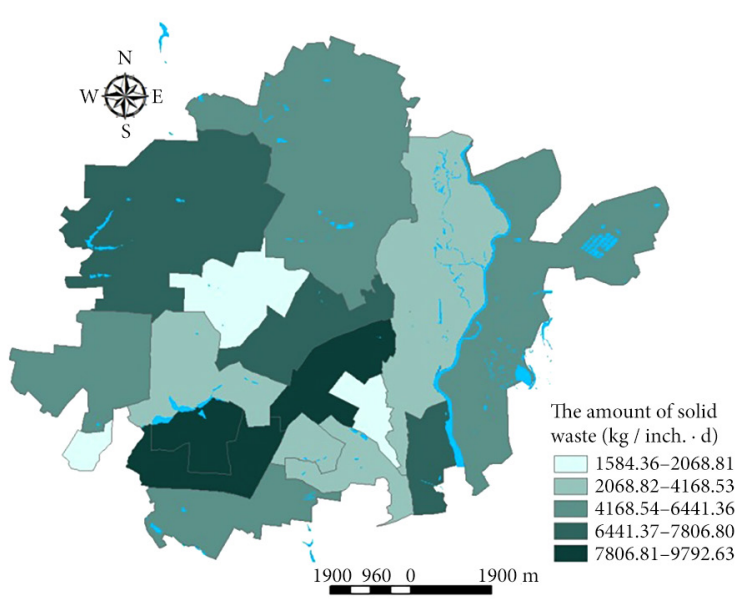

Figure 6. Geoinformation modeling of the urban environment by indicatirs of amount of solid household wastes $(\mathrm{kg} /$ inh. per year) 
The result of this connection is that model studies (calculations) in the MatLab environment can be presented as characteristics of spatial objects with all the advantages of geographic representation and integration with other possibilities of using geo-information technologies. This approach provides a flexible way to use the characteristics of both program environments (Bertalanffy, 2004).

Input data for Poltava city were formed on the basis of the use of an open source: "Poltava 2030. Integrated development of the city" (n.d.). These are regional reports on the state of the environment in the Poltava region for 2015, 2016 years.

In Figure 7 shows the dependence of assessing the effectiveness of the UEM of Poltava city to changes in the amount of solid municipal waste generated by the city population.

On Figure 8, we see the dependence of the metabolism efficiency of Poltava city on the amount of energy for heating buildings.

The graphs shown above show that the sensitivity of the evaluation of the effectiveness of UEM is different depending on the change of the studied variables. For example, if the population of the city reduces the formation of solid household waste by $0.1 \frac{t}{\text { person }}$ per year, then this provides an increase in the efficiency of the urban environment by $5 \%$. At the same time, reducing the amount of energy consumed for heating buildings and structures by $10 \mathrm{kWh} / \mathrm{m}^{2}$ provides an increase in the efficiency of UEM by $8-10 \%$. In Figure 9 shows the UEM efficiency landscape, depending on the amount of energy consumed for the heating of buildings and produced solid household waste.

This can be interpreted as a kind of terrain of the effectiveness of the UEM of Poltava city, depending on the relevant factors of influence.

In Fig. 10 shows a comparison of calculated estimates of the efficiency of UEM in Poltava city (see Table 2) with similar estimates for the cities of Barcelona and Lugano (Acebillo \& Maggi, 2008).

Table 2. Interim estimates of the UEM efficiency indicator in the city of Poltava

\begin{tabular}{|l|l|c|c|c|c|}
\hline \multicolumn{2}{|c|}{$\begin{array}{l}\text { Subsystems of the } \\
\text { municipal economy }\end{array}$} & $N(t)$ & $P(t)$ & $L(t)$ & $\begin{array}{c}\text { Estimates of } \\
\text { efficiency of UEM } \\
\text { of Poltava city }\end{array}$ \\
\hline 1. & $\begin{array}{l}\text { Transport } \\
\text { subsystem }\end{array}$ & 4 & 15.5 & 23.5 & 26 \\
\hline 2. & $\begin{array}{l}\text { Subsystem of } \\
\text { city economy }\end{array}$ & 5 & 34 & 35 & 26.5 \\
\hline 3. & $\begin{array}{l}\text { Socio-economic } \\
\text { subsystem }\end{array}$ & 24 & 70 & 68 & 53 \\
\hline
\end{tabular}

The last estimations received within the limits of the program of monitoring of metabolism of cities of the European Union (Bettencour, Lobo, Helbing, Kühnert, \& West, 2007).

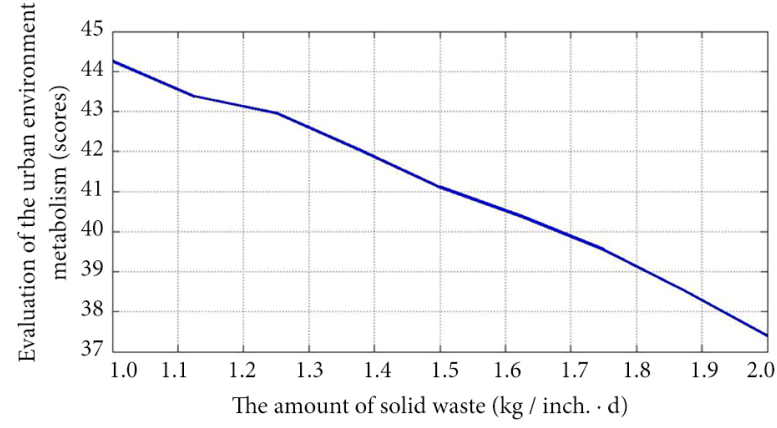

Figure 7. Dependence of the urban environment metabolism Poltava city from the amount solid household waste

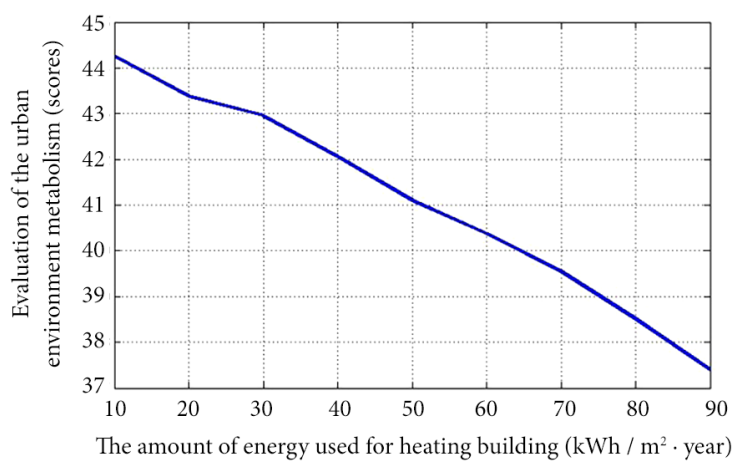

Figure 8 . The dependence of the efficiency of the metabolism of the urban environment of Poltava city on the amount of energy consumed for building heating

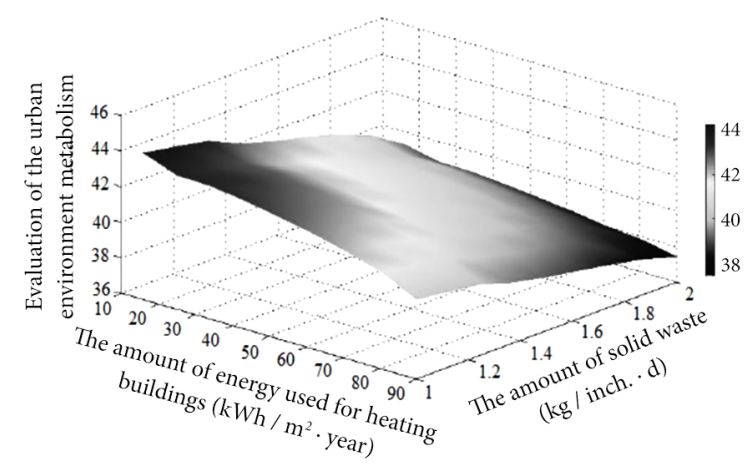

Figure 9. The landscape of the efficiency of the urban environment metabolism Poltava city, depending on the amount of energy consumed for the heating of buildings and municipal solid waste produced by the population

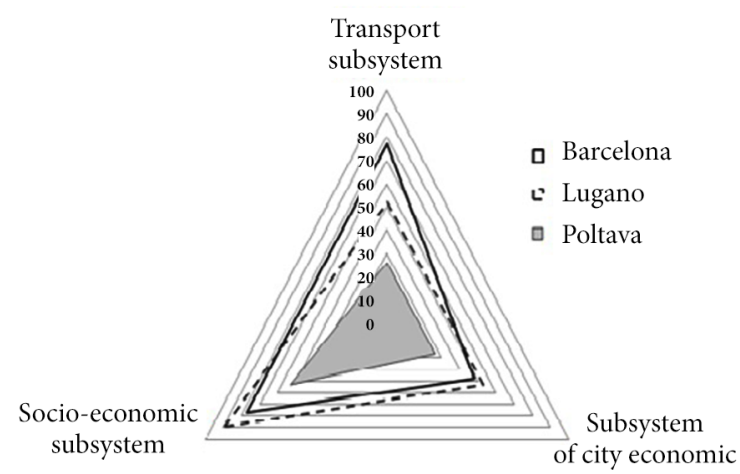

Figure 10. Comparison of estimates of the metabolism efficiency urban environment of Poltava, Barcelona, Lugano 


\section{Conclusions}

A promising approach to reducing environmental impacts is the analysis of metabolic transformations of the real, water, energy, and information flows in the urban environment. In this article, the fuzzy model of the indicator of the evaluation of the effectiveness of the metabolism of the urban environment is proposed, based on fuzzy logic. The use of the indicator of the effectiveness of UEM makes it possible to significantly expand the capabilities of the subsystems of city planning decisions (European Green City Index, 2009). For example, you can perform clustering of functional areas of the city based on selected indicators. This approach allows you to define cadastral districts or administrative units of a city with similar characteristics. These cadastral areas can be compared by the same characteristics. For example, we can compare energy consumption and population density, the use of renewable energy and gross domestic product, the annual energy consumption of industrial enterprises and the volume of $\mathrm{CO}_{2}$ emissions, and so on.

The requested indicator can be used as a tool for a city planner to justify measures that will keep the productivity of the urban environment. That is, this tool can help solve the problem of ensuring implementation of the strategy of building a carbon-free and resource-efficient urban environment. It should be noted that the future direction of perfection and testing of this indicator of the evaluation of the effectiveness of UEM is related to the evaluation of metabolic transformations by the example of other Ukrainian cities. These estimates can be compared to the similar results of the monitoring of metabolism in the European Union cities, carried out under the Sustainable Urban Metabolism for Europe program (SUME) (Bettencour et al., 2007).

\section{References}

Acebillo, J., \& Maggi, R. (2008). LNL - La Nuova Lugano, Visioni, sfide e territorio della citta. Lugano: CUP-IRE.

Allen, S. (2009). Points and lines: Diagrams and projectsfor the city. New York: Princeton Architectural press.

Bertalanffy, L. V. (2004). Teoria generate dei sistemi: fondamenti, sviluppo, applicazioni. Milano: Mondadori.

Bettencour, L. A., Lobo, J., Helbing, D., Kühnert, C., \& West, G. B. (2007). Growth, innovation, scaling, and the pace of life in cities. In Proceedings of the National Academy of Sciences, 104(17), 7301-7306. https://doi.org/10.1073/pnas.0610172104

Bolshakov, B. Y. (2002). Scientific groundwork for design in the system "nature - society - man". Moscow - SPb. - Dubna: Gumanistika.

Butera, F., \& Caputo, P. (2008). Planning eco-cities, the case of Huai Rou New Town. Paper presented at Proceedings of the 3rd International Solar Cities Congress, Adelaide.
Chekmarev, A. (2010). Qualimetry and quality management. Part 1. Qualification textbook. Samara: Samara Publishing House.

European Green City Index. (2009). Assessing the environmental impact of Europe's major cities. Research project conducted by the Economist Intelligence Unit - Munich: Siemens AG.

Enkvist, P., Naucler, T., \& Rosander, J. (2007). A cost curve for greenhouse gas reduction. McKinsey Quarterly, No. 2.

Haurie, A., \& Viguier, L. (2004). The coupling of climate and economic dynamics. Essays on integrated assessment. Vienna: Springer. https://doi.org/10.1007/1-4020-3425-3

Harvey, D. (2011). Megacities Lecture 4. Amersfort: Twynstra Gudde Management Consultants.

Karavaeva, N. I., Levchenko, L. A., \& Trohimenko, J. M. (2011). Analysis of approaches to formation of systems of indicators of sustainable development. Collection of scientific works "Management of development of complex systems", 7, 126-131.

Kennedy, C., Cuddihy, J., \& Engel-Yan, J. (2007). The changing metabolism of cities. Journal of Industrial Ecology, 11(2), 4359. https://doi.org/10.1162/jie.2007.1107

Lotka, A. J. (1998). Analytical theory of biological populations. USA: Springer. https://doi.org/10.1007/978-1-4757-9176-1

Lozano, S., \& Gutierrez, E. (2008). Non-parametric frontier approach to modelling the relationships among population, GDP, energy consumption and $\mathrm{CO}_{2}$ emissions. Ecological Economics, 66(4), 687-699.

https://doi.org/10.1016/j.ecolecon.2007.11.003

Newman, P. (2004). Sustainability and cities: extending the metabolism model. Landscape and Urban Planning, 44(4), 219226. https://doi.org/10.1016/S0169-2046(99)00009-2

Odum, E. (1998). Ecological vignettes: Ecological approaches to dealing with human predicaments. Harwood Academic Publishers.

Patrakeyev, I. M. (2015). An Ontological study of an urban environment. Collection of scientific works "Management the development of complex systems", 1(23), 159-168.

Paola, C., Giulia, P., \& Marco, B. (2016). Urban metabolism analysis as a support to drive metropolitan development world. Procedia Engineering, 161, 1588-1595. https://doi.org/10.1016/j.proeng.2016.08.631

Poltava 2030. Integrated development of the city (n.d.). Retrieved from http://www.2030.poltava.ua

Santamouris, M. (2004). Cooling the cities. Rafraichir les Villes. Paris: Ecole des Mines de Paris.

Tistol, N. I. (2013). Conceptual approach to evaluating the quality of the residential environment. Collection of Scientific Works "Management the Development of Complex Systems", 13, 130-135.

Urban development and urban metabolism: A spatial approach. (2013). Retrieved from http://sume.at/project_downloads

Yanshin, A. L. (2007). The Doctrine of V. I. Vernadsky about biosphere and modernity. In Towards sustainable development (pp. 39-61). Moscow. 